\title{
Storm Induced Water Levels In Norfolk Virginia And Chesapeake Bay: A Model And Observations
}

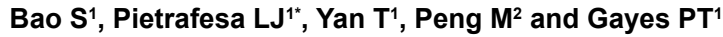 \\ ${ }^{1}$ School of Marine and Coastal Systems Science, Coastal Carolina University, Conway, South Carolina, USA \\ ${ }^{2}$ National Oceanic and Atmospheric Administration National Ocean Service, Rockville, MD
}

\begin{abstract}
An assessment of storm induced water levels in Norfolk Virginia (VA) and Chesapeake Bay using an interactively coupled wave and current numerical model driven by a numerical atmospheric model versus actual observations is presented. The reason for the interactive coupling is that this type of model coupling has been found to greatly improve coastal inundation modeling in another coastal domain. The model system is applied in an area where coastal flooding is likely to increase in the near future and beyond, because the Norfolk VA area has been found to be a "hot spot" along the eastern seaboard as regards rising coastal water levels along the U.S. Atlantic Eastern Seaboard. To assess the variability of sea level we conducted an empirical decomposition of the Sewell's Point water level data and found that there are eight modes of variability ranging from monthly to seasonal to annual to inter-annual to 5-7 years to 10-12 years to about 25 years, with an overall upward trend which has varied from 0.35 t0 $0.85 \mathrm{~cm} /$ year and is presently 0.65 $\mathrm{cm} /$ year. As modes 1 through 7 all have separate temporal periods of oscillation it is unlikely for all seven modes to be positive or negative at any particular time, however that occurrence is a possibility, and if that were to occur, the base water level could be 20 or $35 \mathrm{~cm}$ or $50 \mathrm{~cm}$ higher. Our numerical model results are validated against National Oceanic and Atmospheric Administration (NOAA) National Weather Service (NWS) observed wind fields, and National Ocean Service (NOS) water levels and surface gravity wave significant wave field heights, collected in the Chesapeake Bay domain, show excellent agreement. Given our documented assessment of the variability of coastal water level along the southern VA coastline, future, hurricanes and winter cyclones will subject the Norfolk region to far more coastal inundation and flooding in excess and more frequently than what it has experienced in the past. Norfolk residents will very likely experience frequent "nuisance" flooding and coastal erosion during periods of even moderately strong atmospheric winds associated with the passages of typical winter storms, especially Mid-Latitude cyclones and tropical cyclones; especially during high tides.
\end{abstract}

Keywords: Coupled wave-current model; Water levels; Norfolk Virginia; Chesapeake bay; Nuisance flooding; Catastrophic flooding

\section{Introduction}

The issue of whether or not sea level variability and rise could alter future storm induced inundations in coastal environments is of critical societal concern, and in the Norfolk VA area, of Department of Defense U.S. Navy concern as well. Existing three dimensional hydrodynamic models have attempted to simulate coastal and estuary surge and inundation during the passage of storms; given sea level variability and rise. Many efforts have been made to predict future flooding scenarios under hurricane force conditions but none have utilized a forecast of likely water levels based on a modal decomposition of past water levels and what the likely initial water levels might be if a hurricane or winter storms were to strike a specific locale. This study does that by utilizing an interactively coupled wave-current model system.

ROMS and SWAN are stand-alone, well tested coastal hydrodynamic and wave models, respectively. The Regional Ocean Model System (ROMS) is a free-surface hydrostatic, primitive equation model discretized also with a terrain-following vertical coordinate system [1]. The third-generation shallow water wave model (Simulating WAve Nearshore, SWAN), driven by boundary condition and local winds, is incorporated into the ocean component ROMS model used to simulate the sea level change by computing random, short-crested wind-generated waves in coastal regions and inland waters. SWAN is based on an Eulerian formulation of the discrete spectral balance of action density that accounts for refractive propagation over arbitrary bathymetry and current field [2].

To better simulate a coastal storm surge, and following the prior studies of Davies and Lawrence [3], Liu [4] and Liu et al. [5] demonstrated quite convincingly that an interactively coupled model system, such as the SWAN wave model and the ROM hydrodynamic ocean current model is more realistic in nature than an inactively coupled model system. Those studies demonstrated that the simple addition of wave model output information improved predictions of surge and inundation when taken together versus just employing a circulation model. However, the Liu [4] and Liu et al. [5] interactively coupled model output improved more in their study of the well documented flooding of Charleston SC domain during the passage of Hurricane Hugo in 1989. The results of a wave-current interactively coupled model have never appeared in the peer-reviewed literature for the Chesapeake Bay domain in general and Norfolk VA specifically during the passages of tropical and extra-tropical cyclones. In this study, the coupled ROMS + SWAN model system has been applied to Chesapeake Bay and Norfolk during the passage of a winter storm over the period 12/29/08 - 01/03/09 and during the passage of Hurricane Isabel in the Fall of 2003. Atmospheric winds are modeled using the Advanced Weather Research Forecast model (AWRF).

*Corresponding author: Dr. Leonard J. Pietrafesa, School of Marine and coastal Systems Science, Coastal Carolina University, Conway, South Carolina, USA; Tel: +843 349-4019; E-mail: ljpietra@ncsu.edu

Received December 01, 2015; Accepted December 14, 2015; Published December 21, 2015

Citation: Bao S, Pietrafesa LJ, Yan T, Peng M, Gayes PT (2015) Storm Induced Water Levels In Norfolk Virginia And Chesapeake Bay: A Model And Observations. J Coast Zone Manag 19: 415. doi: 10.4172/2473-3350.1000415

Copyright: (c) 2015 Bao S, et al. This is an open-access article distributed under the terms of the Creative Commons Attribution License, which permits unrestricted use, distribution, and reproduction in any medium, provided the original author and source are credited. 


\section{Model and experimental setup}

Chesapeake Bay is the largest estuary in the United States and is important to the collective economies of Maryland, Virginia and Delaware. As such the studies of the entire system helped establish the basis for our present understandings of how coastal plain estuaries function. More recently, a considerable body of numerical modeling research has been conducted in this area and has contributed to that knowledge base. Many studies have collectively conducted notable studies of tidal and water level hydrodynamic responses of the Chesapeake Bay system under a variety of simulated forcing conditions [6-12]. We note that some Bosley and Hess [6], Valle-Levinson, et al. [7], Boicourt [8], Shen and Gong [11] are especially germane to our study as they focused on storm induced responses; as are we.

For our hydrodynamic current and wave modeling, we employed $100 \times 150$ curvilinear grids as shown in Figure 1 . The model bathymetry was extracted from high resolution Coastal Relief Model data archived at NOAA's National Geophysical Data Center. Among the nine observation stations in Figure 1, six are part of the in-situ Chesapeake Bay Interpretive Buoy System and the other three are National Oceanic and Atmospheric Administration (NOAA) National Ocean Service (NOS) coastal tide gage stations. In Table 1, the geographic positions and the $\mathrm{X}$ and $\mathrm{Y}$ grid index of these stations are presented.

ROMS Version 3.2 was used as our current based in our study. The model includes hydrodynamic, wave and bottom boundary layer shear stress components. This test case involved the two-way coupling of ROMS and the wave model SWAN, directly employing the Modeling Coupling Toolkit (MCT). The details of the model system are presented below.

The Advanced Research WRF (ARW) model was employed to provide the necessarymeteorological forcing input for the ROMS+SWAN interactively coupled model. The domain has rectangular $100 \times 170$ horizontal grids with $4100 \mathrm{~m}$ horizontal resolution. The number of vertical layers is 28 . The conventional ARW regular grid output data had to be interpolated onto the ROMS+SWAN grids. The ARW model/ data output includes surface pressure, relative humidity, temperature, wind speed at the $10 \mathrm{~m}$ above ground and water level mean surface level, net short wave radiation flux, net long wave radiation flux and the average precipitation rate. The time frame of $12 / 27 / 2008$ to $01 / 06 / 2009$ was chosen as the model validation period because a strong winter storm occurred around Jan 1 of 2009 which offered enough forcing to generate noticeable wind waves. Figure 2 shows ARF $10 \mathrm{~m}$ surface wind vectors at $00 \mathrm{Z}$ of January 2009.

Astronomical tidal forcing at the open ocean boundary is specified using the Oregon State University (OSU) global inverse tidal model of TPXO.6.2, which solves the Laplace tidal equations with a grid resolution of 0.251 by 0.251 and assimilates data from tide gauge observations and TOPEX/Poseidon satellite measurements $[13,14]$. Tidal elevation at the open boundary is decomposed into five major tidal constituents, the M2, S2, N2, K1, and O1, using the harmonic constants linearly interpolated from OSU global tidal model. The open-ocean boundary condition consists of a Chapman condition for surface elevation and, a Flather condition for vertically averaged current velocity and radiation condition for 3-D current velocity.

The sub-tidal low-frequency free surface at the open boundary is obtained from $1 / 12^{\circ}$ HYCOM (Hybrid Coordinate Ocean Mode) + NCODA (Navy Coupled Ocean Data Assimilation) global dataset. These regular grid data within the validation period again are interpolated onto the open boundary of the curvilinear ROMS+SWAN grid points.
SWAN is coupled with ROMS by the MCT. ROMS and SWAN have their own time steps which are 300 and 900 seconds respectively. Every 1800 seconds, SWAN and ROMS swap model output data to each other via the MCT. In the process, SWAN passes significant wave height, wave direction, average wave length, surface wave relative peak period, bottom wave period, wave energy dissipation, percent wave breaking and wave bottom orbital velocity to ROMS. In return, ROMS provides SWAN with the updated bathymetry, free surface, vertically integrated $\mathrm{U}$-momentum, vertically integrated $\mathrm{V}$-momentum and bottom roughness.

The necessary wave, open boundary was interpolated from the observed data from the NOAA National Data Buoy Center (NDBC) Station 44014 at $36.611 \mathrm{~N} 74.836 \mathrm{~W}$ and NDBC Station 44100 at $36.258^{\circ} \mathrm{N}$ $75.591^{\circ} \mathrm{W}$. However, unlike the tides, the energy of wind driven short gravity waves dissipates quickly as they propagate into the Bay. Former studies indicate that waves in the middle and upper Chesapeake Bay are generated almost entirely by local wind and the waves, and swells produced in the open ocean are dissipated and reflected near the entrance of the Bay $[15,16]$. The same model system was also used to simulate Hurricane Isabel winds and the inundation of the Norfolk domain during the period prior to, during and following the passage of Isabel, 6-19 September 2003.

\section{Results and Discussion}

The ARW model produced and thus reproduced the storm wind forcing to the coupled model during the 10 day period studied. Figure 3 shows the modeled and observed wind speed and direction at Stingray Point and Jamestown. The average root mean square (rms) difference between the observed and modeled wind speed is 1.2 and $1.1 \mathrm{~m} / \mathrm{s}$ for Stingray Point and Jamestown, respectively so clearly the model replicated the wind field very well. The average rms difference of wind direction is 5.6 and 6.4 degrees for the two stations. The purpose of the wind comparisons at Stingray point and Jamestown is to validate the AWRF model setup; which is used to provide the meteorological forcing in our study. We note also that the storm induced water levels at Norfolk are found to be largely due to non-local wind forcing effects and paradoxically not direct mechanical forcing.

The sea surface elevation and vertically averaged currents at every three hours from 12/31/08 18Z to 1/1/09 03Z are shown in Figure 4. This is during the period of time when the northwesterly wind was the strongest during the event. As the sub-tidal sea level change at the open boundary was small during the event, less than $10 \mathrm{~cm}$ as indicated by observation and HYCOM data, Figure 4 therefore indicates how wind forcing and its induced sea surface set-up and set-down co-exists with the tide.

The M2 semi-diurnal tide, which is a Poincare wave on the continental shelf, propagates around Chesapeake Bay as a Kelvin Wave, with a gravity wave speed of $\sqrt{g h}$, where $g$ is acceleration due to gravity and $h$ is the water depth. Given the fact that Chesapeake Bay is shallow and long $(320 \mathrm{~km})$, it takes more than a tidal period for the signal to propagate from its entrance to the head. Table 2 shows the time of high tide and low tide at three gauge stations on 12/31/08 and 1/1/09. Figure 4 partly reflects this fact. Essentially most the tidal phase at the entrance is similar to that near the head and opposite to that in the middle of the Bay.

At 1/1/09 $03 \mathrm{Z}$ however, the sea level in the vicinity of the head and the mid bay are negative while high tide occurs near the entrance. This is because the water level set-down due to the northwesterly wind was 

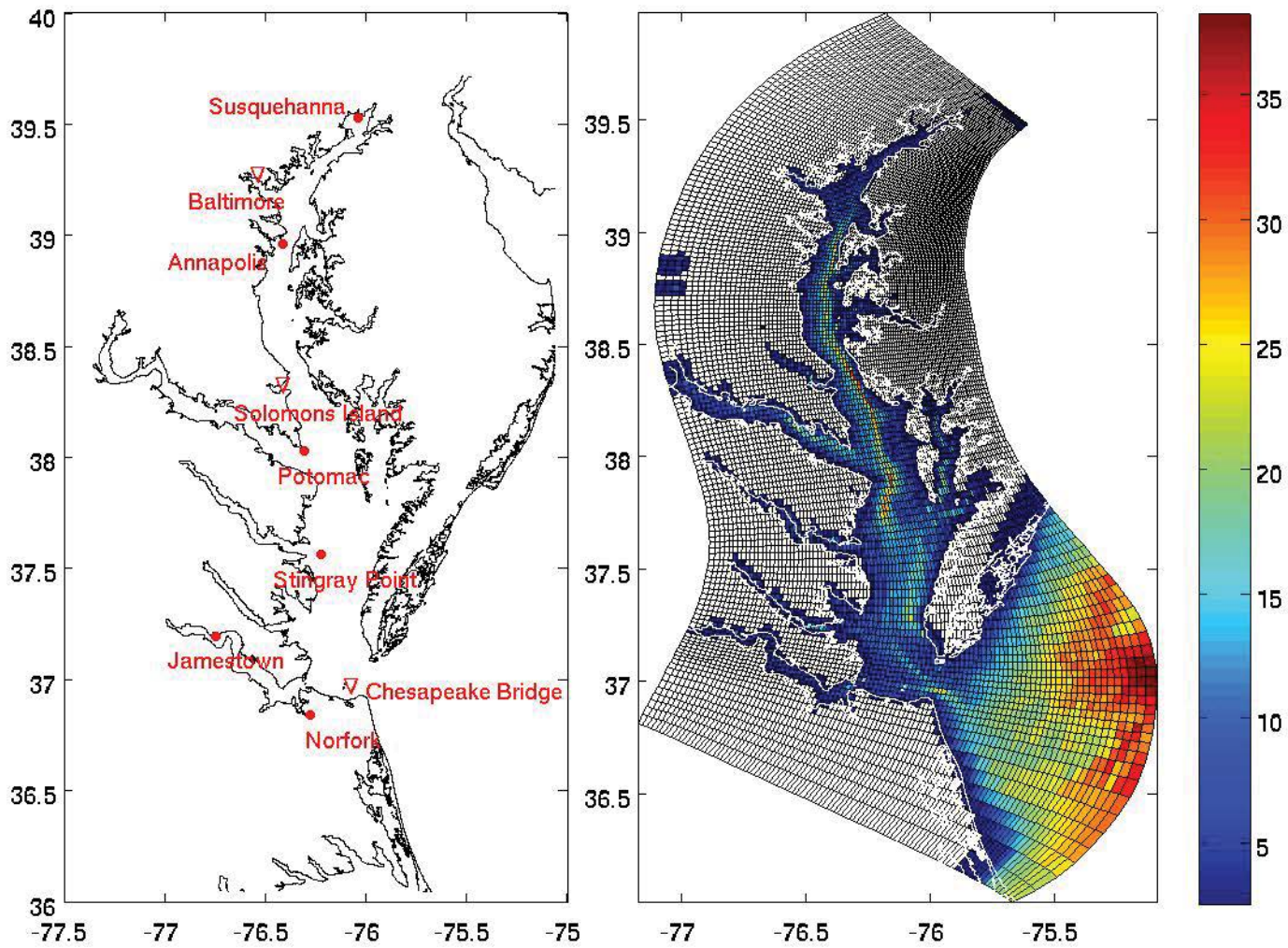

Figure 1: Chesapeake Bay observations stations and model grids.

\begin{tabular}{|c|c|c|c|c|}
\hline Station Name & Latitude & Longitude & Y index & X index \\
\hline Norfolk & 36.8455 & -76.2980 & 8 & 43 \\
\hline Jamestown & 37.2042 & -76.7775 & 20 & 10 \\
\hline Stingray Point & 37.5674 & -76.2572 & 33 & 39 \\
\hline Potomac & 38.0333 & -76.3375 & 49 & 38 \\
\hline Annapolis & 38.9631 & -76.4475 & 98 & 32 \\
\hline Susquehanna & 39.5437 & -76.0748 & 137 & 36 \\
\hline Baltimore & 39.2667 & -76.5783 & 112 & 16 \\
\hline Solomons Island & 38.3167 & -76.4517 & 62 & 33 \\
\hline Chesapeake Bay Bridge & 36.9667 & -76.1133 & 14 & 51 \\
\hline
\end{tabular}

Table 1: The stations and their locations in the model grid.

larger in magnitude than the amplitude of the tide near the Bay head. Meanwhile the strong wind and the consequent southward moving currents overcame the flooding tide and reversed the net current. Instead of a normally strong flooding flow through the entrance, an "ebb" flow continues as shown in the figure. The interaction of tidal and wind driven sea level is shown more clearly in Figure 5. In all those three stations, P-values of the modeled and observed time series are less than 0.01 , means a very significant correlation.

Wave simulation results for the winter storm event are shown in Figure 6. Even under such large wind forcing, the significant wave height $(H s)$ inside the bay is smaller than $2 \mathrm{~m}$. The observed data are available only at Potomac and Jamestown. The comparison of the modeled and observed significant wave height within the entire 10 day period is shown in Figure 7. The simulation captured the trends of the wave height variations. The average rms difference between the observed and modeled $H s$ is 0.14 and $0.08 \mathrm{~m}$ respectively for Potomac and Jamestown. P-value is less than 0.01 .

As shown by the model results versus the data, the model results have been shown to visually replicate the storm forcing very well. We chose not to conduct a statistical assessment of the model results vs the actual data observations, as they were in close visual agreement.

Studies of Boon [12], Boon [17], Sallenger, et al. [18] have conducted very revealing sea level rise studies in the Chesapeake Bay domain. In fact the Salinger et al. [18] study concluded that this area was a U.S. eastern seaboard "hot spot" of sea level rise. To simulate the solid reports of rapidly rising sea level in the Norfolk-Virginia Beach-Sewell's Point area and to look at the potential of flooding in this area with anticipated sea levels of the future, we next conduct an experiment by raising the base level of mean water level prior to the onset of Hurricane Isabel.

In Figures $8 \mathrm{a}$ and $8 \mathrm{~b}$, we have simulated the flood and inundation in the Norfolk VA domain associated with the passage of Hurricane Isabel. It was significant and Figure 8a details the flooding of the streets and residential areas. In Figure $8 \mathrm{~b}$, the streets are removed to yield a contrast to $8 \mathrm{a}$. The perspective is quite dramatic. However, as future stands of sea level may be much higher than they have in the past [18], we will investigate the outcomes of those potential new realizations. 


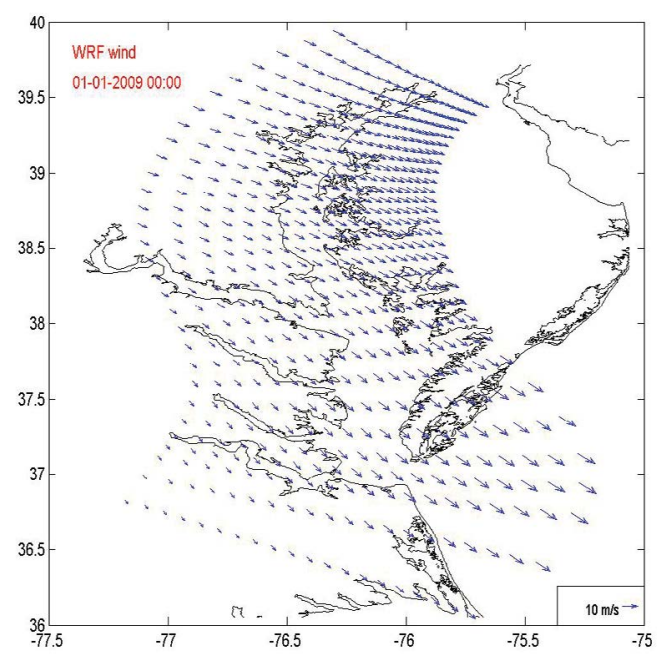

Figure 2: ARW wind fields interpolated at every five ROMS+SWAN grid points $(20 \times 30)$.
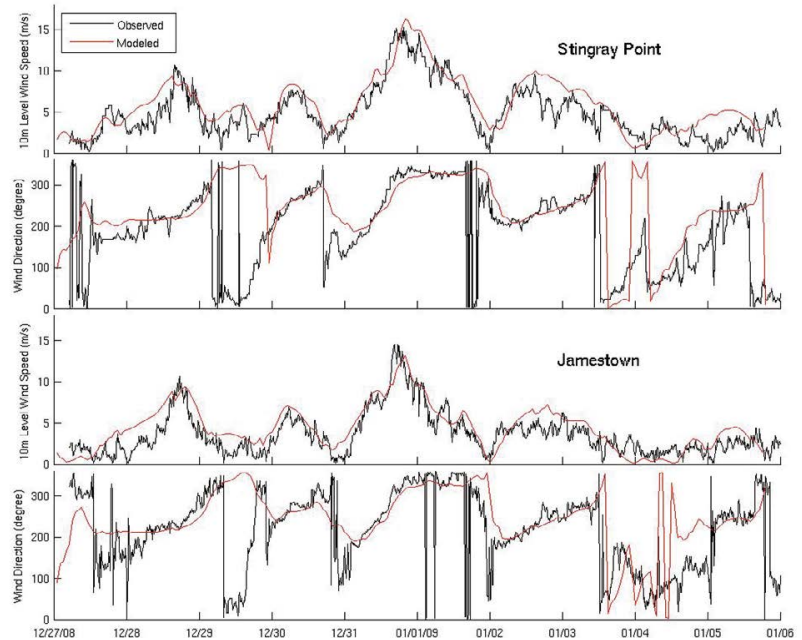

Figure 3: ARW modeled wind speed and directions compared with observations at Stations Stingray Point and Jamestown.

In an effort to better assess what future flooding scenarios may be in store for this locale we will take an in depth look at sea level variability at Sewell's Point. We will conduct a Hilbert Huang Transform [19] of the time series of water levels at Sewell's Point to assess the temporal modes of water level variability that are buried within the time series. Thus we will consider not just the overall trend of sea level rise but the actual modes of variability and evaluate those potential flooding outcomes.

In Figure $8 \mathrm{~b}$, we see the inundation in the Norfolk sector in the presence of a $50 \mathrm{~cm}$ greater height in sea level at the onset of the event. As can be seen, the entire Norfolk domain is underwater and ships berthed may be dry-docked. This is an ominous result. So, when might

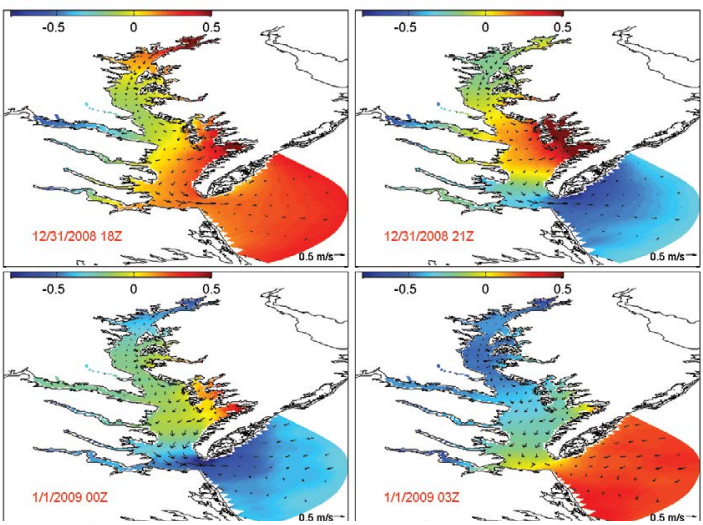

Figure 4: Sea surface elevation and vertically averaged currents.

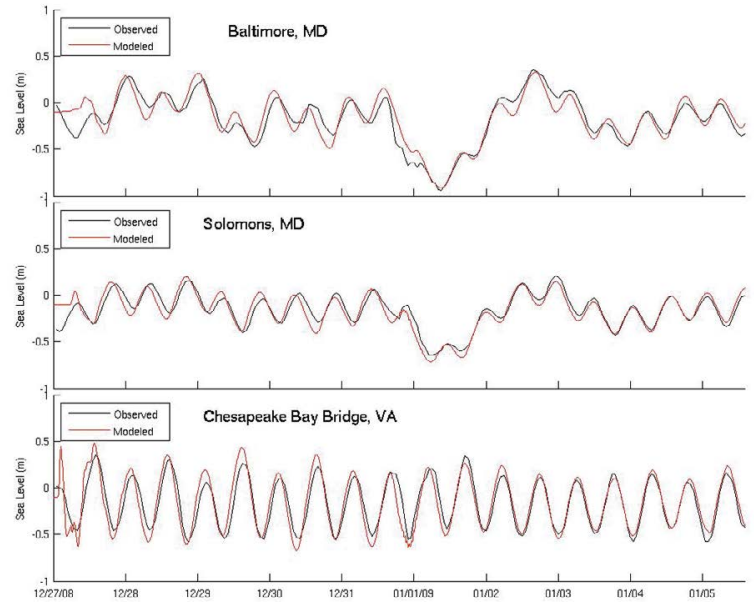

Figure 5: Comparison of modeled sea surface elevation with observations at three stations in Chesapeake Bay.

that rise occur? perhaps sooner than anyone thinks.

When the notion of sea level rise is discussed, it is presumed to be a continual upward march at very small annual rates of rise. In Figure 9, we see that from 1927 to 2010, sea level at Sewell's Point, near Norfolk, has displayed an overall upward trend with rates of rise which have varied between $0.85 \mathrm{~cm} / \mathrm{yr}$ to $0.35 \mathrm{~cm} / \mathrm{yr}$ to a modern rate of $0.65 \mathrm{~cm} / \mathrm{yr}$.

Next, if we conduct an EEMD decomposition of the Sewell's Point water level data, shown in Figure 10, we see that there are actually eight modes of variability ranging from monthly to seasonal to annual to inter-annual to 5-7 years to $10-12$ years to about 25 years, with an overall upward trend. Modes $\mathrm{C} 1$ to $\mathrm{C} 7$ all have separate temporal periods of oscillation. As such, it is unlikely for all seven modes to be positive or negative at any particular time, however that occurrence is a possibility. If that were to occur, then mean water level would be $7 \mathrm{~cm}$ higher in 2015 than it was in 2003 when Isabel struck. If all modes were positive, then that would add another $25-30 \mathrm{~cm}$. Then we must account for the seasonal summer to fall steric rise of the North Atlantic Ocean which could be as much as 5 to 10 to $15 \mathrm{~cm}$ higher than it was in 2003; as shown in Mode 2 in Figure 10. Thus the base water level could be 20 
Citation: Bao S, Pietrafesa LJ, Yan T, Peng M, Gayes PT (2015) Storm Induced Water Levels In Norfolk Virginia And Chesapeake Bay: A Model And Observations. J Coast Zone Manag 19: 415. doi: 10.4172/2473-3350.1000415

Page 5 of 7

\begin{tabular}{|c|c|c|c|}
\hline \multicolumn{1}{|c|}{ Stations } & High tide & Low tide & High tide \\
\hline Chesapeake Bay Bridge & $15: 20(d 1)$ & $21: 40(d 1)$ & $3: 45(\mathrm{~d} 2)$ \\
\hline Solomons Island & $21.45(d 1) 2: 20$ & $9: 00(\mathrm{~d} 2)$ & $9: 55(\mathrm{~d} 2)$ \\
\hline Baltimore & $(\mathrm{d} 2)$ & $9: 15(\mathrm{~d} 2)$ & $14: 30(\mathrm{~d} 2)$ \\
\hline
\end{tabular}

Table 2: Tide table at three stations on $12 / 31 / 08$ and 1/1/09.

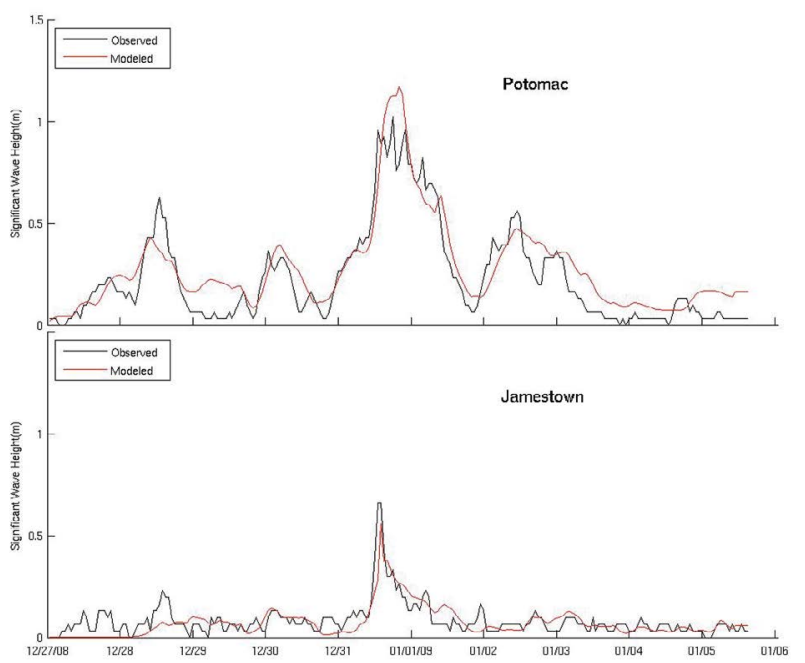

Figure 6: Significant wave height during the winter storm event.

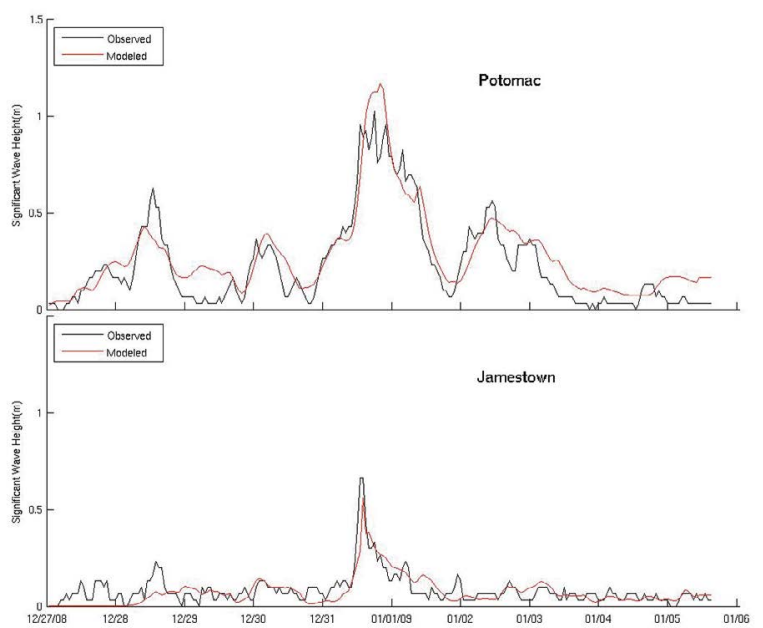

Figure 7: Comparison of modeled significant wave height with observations at stations in Chesapeake Bay.

$\mathrm{cm}$ or $35 \mathrm{~cm}$ or even $50 \mathrm{~cm}$ higher.

In Figure 11, we conduct four experiments for comparison. Our numerical model is run for the time series of water levels at Sewell's point for Isabel as the Base Case, for $20 \mathrm{~cm}$ above Isabel's initial or zero water level, for $35 \mathrm{~cm}$ above Isabel's initial water level and finally for 50 $\mathrm{cm}$ above Isabel's zero water level.

In Figure 12, our model output of the inundation of the Norfolk

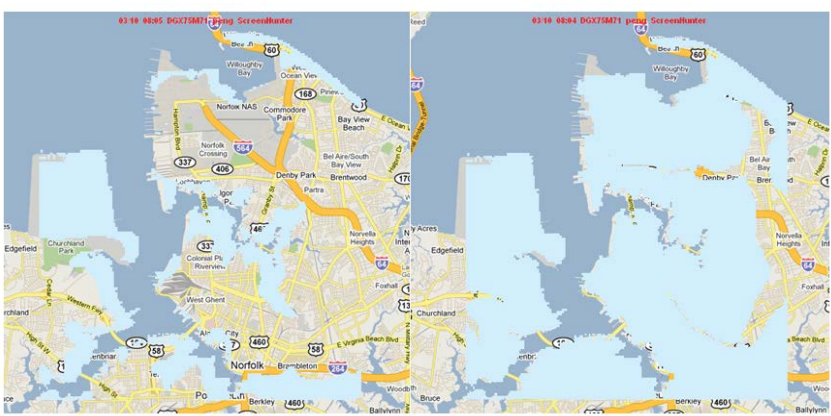

Figure 8: Flooding and inundation of the Norfolk VA domain (a) due to the passage of Hurricane Isabel in 6-19 September 2003. (b) same locale as panel (a) but with roads removed.

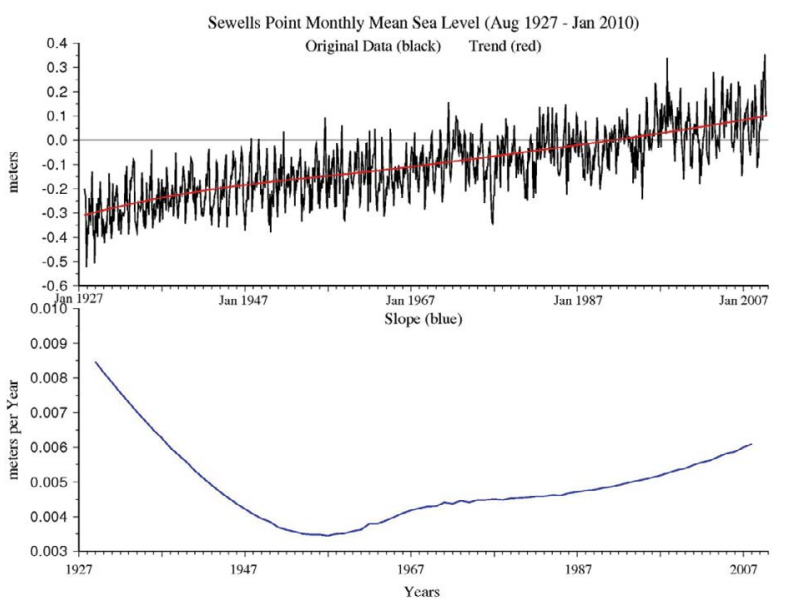

Figure 9: Water level at Sewell's Point from 1927 - 2010. The red line in the upper panel is the trend and the blue line in the lower panel is the yearly rate of change of the trend line.

domain is shown with an initial water level of $50 \mathrm{~cm}$ above that which was present when Isabel struck. That initial water level could occur as the base of water level when the next hurricane strikes the area. Sea level rise in the area and the seasonal static rise observed in the water level records. Panel (a) shows the flooding with roads included. Panel (b) shows the flooding with the roads removed.

\section{Conclusions}

We have utilized an interactively coupled wave- current model driven by a modern atmospheric model to generate water level time series during the passages of two atmospheric storms, both actual 


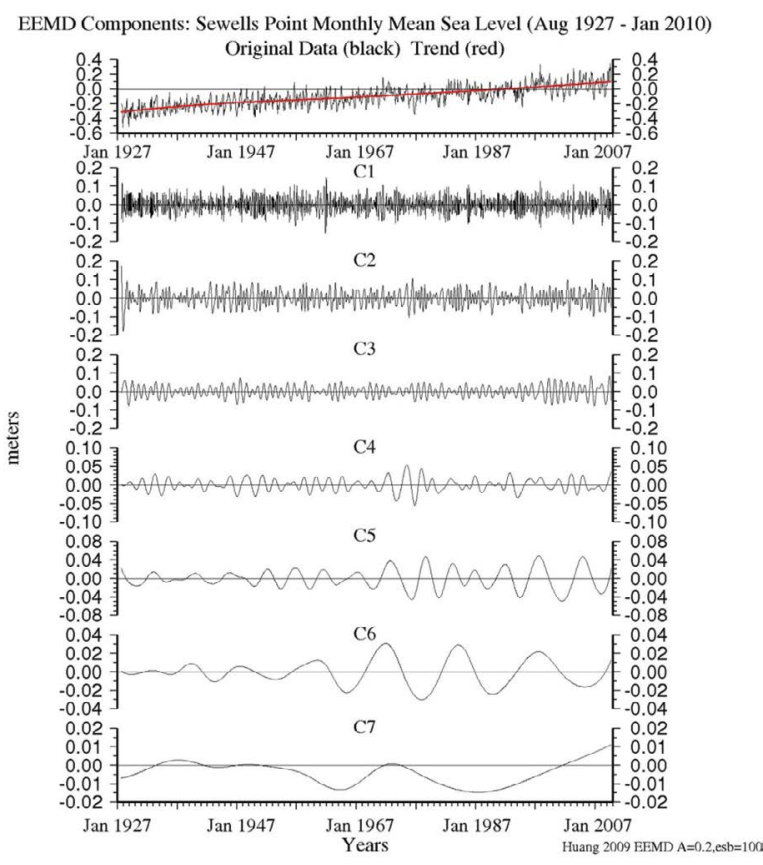

Figure 10: EEMD components of water level at Sewell Point.

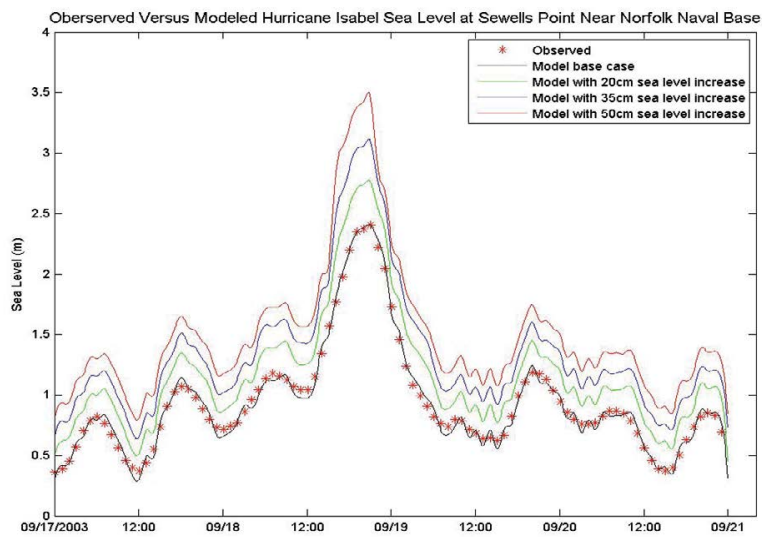

Figure 11: Comparison of observed and modeled sea level at Sewells Point.

storms. One was an Extra-Tropical, Mid-Latitude winter storm and the other a hurricane. The observed water levels in and around Chesapeake Bay and the model results were very close demonstrating the power of the model system in being able to produce robust diagnostic results and also offering a reliable, validated prognostic tool.

Given the reported and documented rise of coastal water level along the southern VA coastline [18], and the continuing rate of rise that we report upon above, it has become clear that in the future, hurricanes and winter cyclones will subject the Norfolk region to significant coastal inundation and flooding; of a type not yet seen in the past. Moreover, given the rise of sea level in this region, Norfolk residents will very likely experience nuisance flooding and coastal erosion during
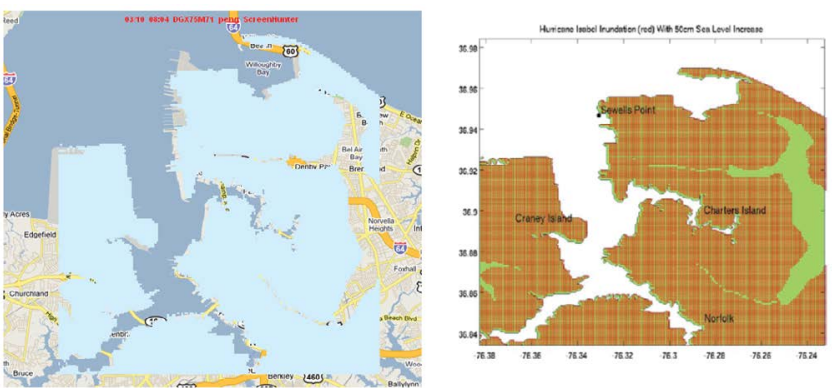

Figure 12: Inundation of the Norfolk - Sewell's Point VA region for a case of $50 \mathrm{~cm}$ higher levels of coastal water levels above what has been accepted as zero in that area but is no longer given the overall sea level rise in the area and the seasonal static rise observed in the water level records. Panel (a) shows the flooding with roads included. Panel (b) shows the flooding with the roads removed.

periods of even moderately strong atmospheric winds associated with the passages of typical winter storms; especially during high tides.

Additionally, in a pioneering publication, Pietrafesa et al. [20] documented the importance of tracking precipitation prior to and during wet atmospheric storms in diagnostically and prognostically determining the flooding and inundation past and likely future outcomes. Dube et al. [21] and Pietrafesa et al. [22] demonstrated the importance of a more comprehensive approach to coastal surge, flooding and inland inundation via the incorporation of rainfall and river discharge, demonstrating that without consideration of the above factors, coastal and inland flooding can be underestimated by a documented 900 percentage (eg., $200 \mathrm{~km}^{2}$ vs $1800 \mathrm{~km}^{2}$ in Pamlico Sound North Carolina the passage of Hurricane Floyd in 1999). While this was not done in our Chesapeake Bay study reported on within, it should be considered in future studies of flood and inundation in that heavily populated domain.

\section{Acknowledgements}

The authors acknowledge support for this study by the NOAA Chesapeake Bay Modeling Program funded through the University of Maryland Grant No. 528496 though the advanced Studies Institute. Coastal Carolina University's FIGI Computational Platform was used for the model computations. The Coastal Carolina University School of Coastal and Marine Systems Science provided institutional support for the study.

\section{References}

1. Haidvogel DB, Arango $\mathrm{H}$, Budgell WP, Cornuelle BD, Curchister $\mathrm{E}$, Di Lorenzo E, et al. (2008) Ocean forecasting in terrain-following coordinates: Formulation and skill assessment of the Regional Ocean Modeling System. Journal of Computational Physics 227: 3595-3624

2. Ris RC, Holthuijsen LH, Booij N (1999) A third-generation wave model for coastal regions: Verification. Journal of Geophysical Research: Oceans (19782012) 104: 7667-7681.

3. Davies AM, Lawrence J (1995) Modeling the Effect of Wave-Current Interaction on the Three-Dimensional Wind-Driven Circulation of the Eastern Irish Sea. Journal of Physical Oceanography 25: 29-45.

4. Liu H (2006) Analysis and modeling of Wave-Current Interactions. Dissertation North Carolina State University: 110.

5. Liu H, Xie L, Pietrafesa LJ, Peng M (2008) The effect of wave-current interactions on the storm surge and inundation in Charleston Harbor during Hurricane Hugo 1989. Ocean Modelling 20: 252-269.

6. Bosley KT, Hess KW (2001) Comparison of statistical and model-based hindcasts of subtidal water levels in Chesapeake Bay. Journal of Geophysical Research 106: 16869-16885 
Citation: Bao S, Pietrafesa LJ, Yan T, Peng M, Gayes PT (2015) Storm Induced Water Levels In Norfolk Virginia And Chesapeake Bay: A Model And Observations. J Coast Zone Manag 19: 415. doi: 10.4172/2473-3350.1000415

7. Valle-Levinson A, Wong K, Bosley KT (2002) Response of the lower Chesapeake Bay to forcing from Hurricane Floyd. Continental Shelf Research 22: $1715-1729$.

8. Boicourt WC (2005) Physical response of Chesapeake Bay to hurricanes moving to the wrong side: Refining the forecasts. In Hurricane Isabel in Perspective. Sellner KG (eds): 39-48.

9. Shen J, Wang H, Sisson M, Gong W (2006) Storm tide simulation in the Chesapeake Bay using an unstructured grid model. Estuarine, Coastal and Shelf Science 68: 1-16.

10. Guo X, Valle-Levinson A (2008) Wind effects on the lateral structure of densitydriven circulation in Chesapeake Bay. Continental Shelf Research 28: 2450 2471.

11. Shen J, Gong W (2009) Influence of model domain size, wind directions and Ekman transport on storm surge development inside the Chesapeake Bay: A case study of extratropical cyclone Ernesto, 2006. Journal of Marine Systems 75: $198-215$

12. Boon JD (2012) Evidence of sea level acceleration at U.S. and Canadian tide stations, Atlantic Coast, North America. Journal of Coastal Research 28: 14371445.

13. Egbert GD, Bennett AF, Foreman MGG (1994) TOPEX/POSEIDON tides estimated using a global inverse model. J of Geophysical Research 99: 24821 24852.

14. Egbert GD, Erofeeva SY (2002) Efficient inverse modeling of barotropic ocean tides. J. Atmos. Oceanic Technol 19: 183-204.

15. Boon JD, Green MO, Suh KD (1996) Bimodal wave spectra in lower
Chesapeake Bay, sea bed energetics and sediment transport during winter storms. Continental Shelf Research 16: 1965-1988.

16. Lin W, Sanford LP, Suttles SE (2002) Wave measurement and modeling in Chesapeake Bay. Continental Shelf Research 22: 2673-2686.

17. Boon JD, Brubaker JM, Forrest DR (2010) Chesapeake Bay Land Subsidence and Sea Level Change: an Evaluation of Past and Present Trends and Future Outlook. A report to the U.S. Army Corps of Engineers, Norfolk District. Special Report in Applied Marine Science and Ocean Engineering No. 425, Virginia Institute of Marine Science: 72

18. Sallenger Jr AH, Doran KS, Howard PA (2012) Hotspot of accelerated sea-leve rise on the Atlantic coast of North America. Nature Climate Change: 2.

19. Huang NE, Shen Z, Long SR, Wu MC, Shih HH, et al. (1998) The Empirical Mode Decomposition and the Hilbert Spectrum for Nonlinear and Nonstationary Time Series Analysis. Proceedings of the Royal Society of London A 454 1971: 903-995.

20. Pietrafesa LJ, Dickey D, Xie L (2000) The surge and flood due to Hurricanes Floyd and Dennis. Chapter No. 2 in the East Carolina University Press publication: Flooding in Eastern North Carolina due to Hurricane Floyd 1999 (Editor) Maola D.

21. Dube SK, Sinha PC, Rao AD (2005) Effect of the Mahandi River on the Development of Storm Surge Along the Orissa Coast of India: A Numerical Study. Pure Applied Geophysics 162: 173-1688.

22. Pietrafesa LJ, Kelleher K, Peng M, Bao S (2006) A New Architecture for Coastal Inundation and Flood Warning Prediction. Journal of Marine Technology Society: 40: 71-77. 